\title{
Radiological features of simple (unicameral) bone cysts
}

Jaco du Plessis, MBChB
Savvas Andronikou, MB BCh, FCRad, FRCR
(Lond), PhD
Murray Hayes, MBChB
Ayanda Mapukata, MB ChB
Department of Radiology, Tygerberg Hospital,
Stellenbosch University, Tygerberg

When encountering a radiologically benign lucent bone lesion in a child, a simple bone cyst is a reasonable diagnostic consideration. Simple or unicameral bone cysts are expansile, serous-fluid-containing defects, that are not true neoplasms. Peak age ranges between 3 and 14 years in $80 \%$ of cases. The incidence is estimated at $3 \%$ of all bone lesions, with a male to female ratio of $2: 1{ }^{1}$ The aetiology of these lesions is poorly understood. Various hypotheses have included dysplastic processes, synovial cysts, and abnormalities in the local circulation. The majority (94\%) of these cysts occur in the proximal humerus and femur. ${ }^{2}$ Less frequent sites include the calcaneus (2\%), ilium (2\%), talus, tibia and

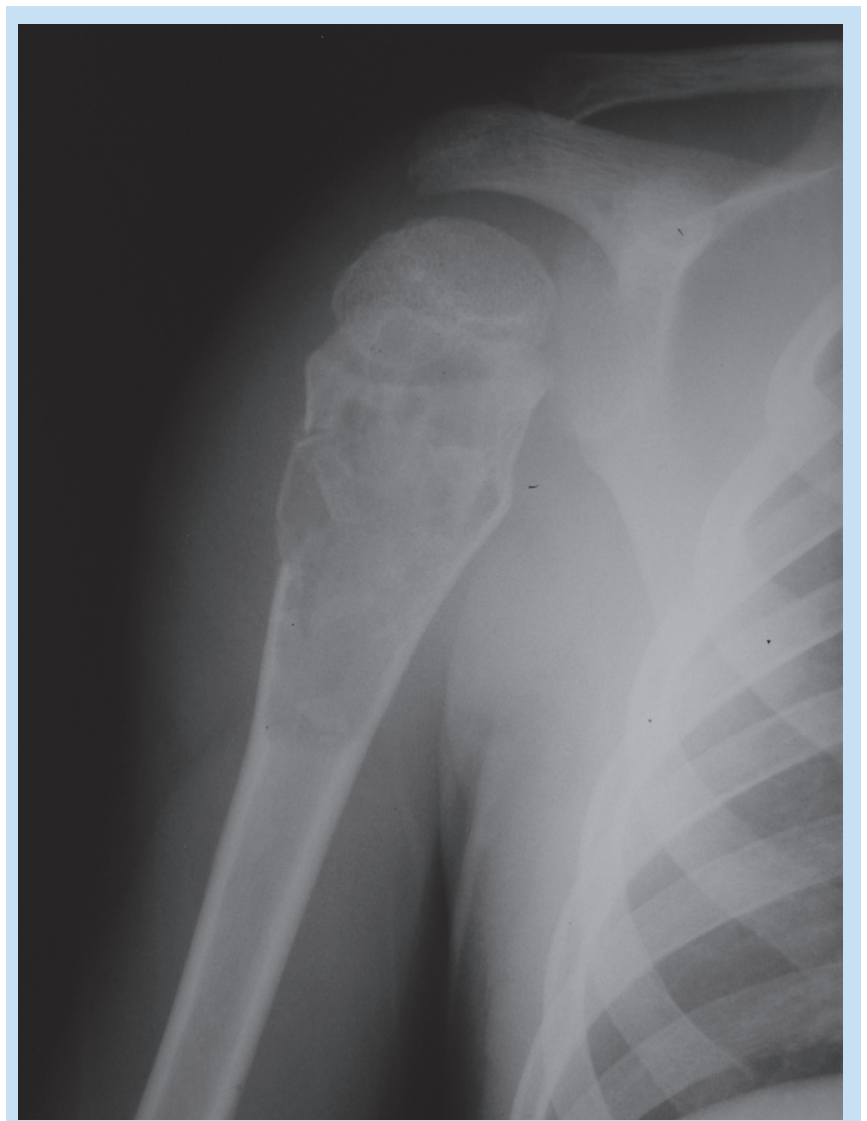

Fig. 1. An expansile medullary, radiolucent lesion in the proximal humeral metaphysis extending to the growth plate is seen. This is the appearance of a simple bone cyst. A common complication is a pathological fracture which is seen to disrupt the cortex laterally in this patient.

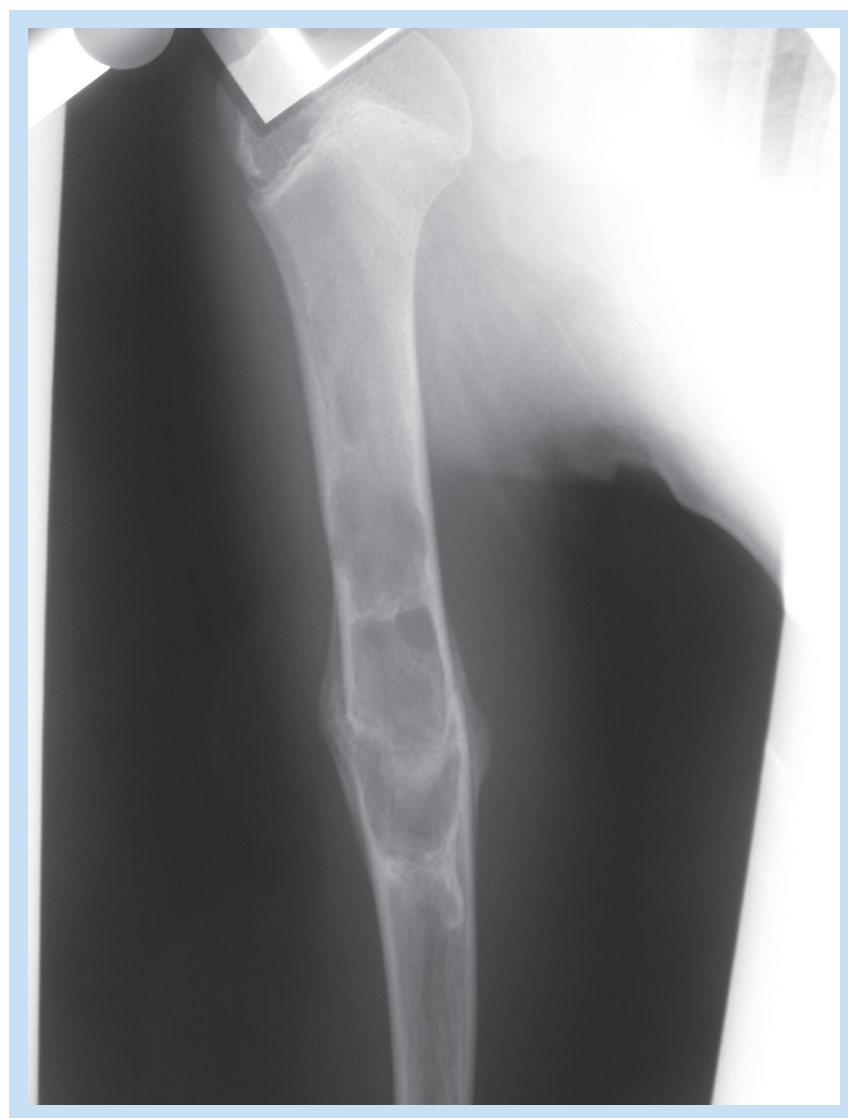

Fig. 2. In addition to the visualised pathological fracture, a 'fallen fragment' is demonstrated which is almost pathognomonic of a simple bone cyst.

fibula. ${ }^{3}$ Most often a single bone is affected. ${ }^{4}$ The most common complication, a non-displaced pathological fracture (66\% of cases), is often the presenting complaint.

The radiological features on plain radiographs include a centrally (medullary) located, expansile lesion of the metaphysis (Fig. 1). Cortical thinning without disruption is seen. ${ }^{2}$ As a result of the fracture and the fact that this is a hollow/fluid-filled unicameral lesion, a 'fallen fragment/leaf' may be visualised (Fig. 2). The 'fallen leaf' sign is virtually pathognomonic of a multiloculated bone cyst. ${ }^{5}$ This distinguishes it from other low-density lesions such as an aneurysmal bone cyst, which is more septated or contains a more solid matrix. Follow-up X-rays demonstrate that the growth plate moves away from the cyst as the child grows (Fig. 3). This explains why two-thirds of these lesions are not in contact with the growth plate when discovered in children older than 10 years. ${ }^{6} \mathrm{CT}$ can be useful to evaluate the extent of the cyst, especially if pelvic bones are affected. Hounsfield units will help to differentiate lipomas from fluid-filled cysts. ${ }^{7}$ Typically MRI will demonstrate a lowsignal intensity on T1-weighted images and high-signal intensity on T2weighted images in the typical simple bone cyst. ${ }^{7}$ Double-density fluid 


\section{CASE REPORT}

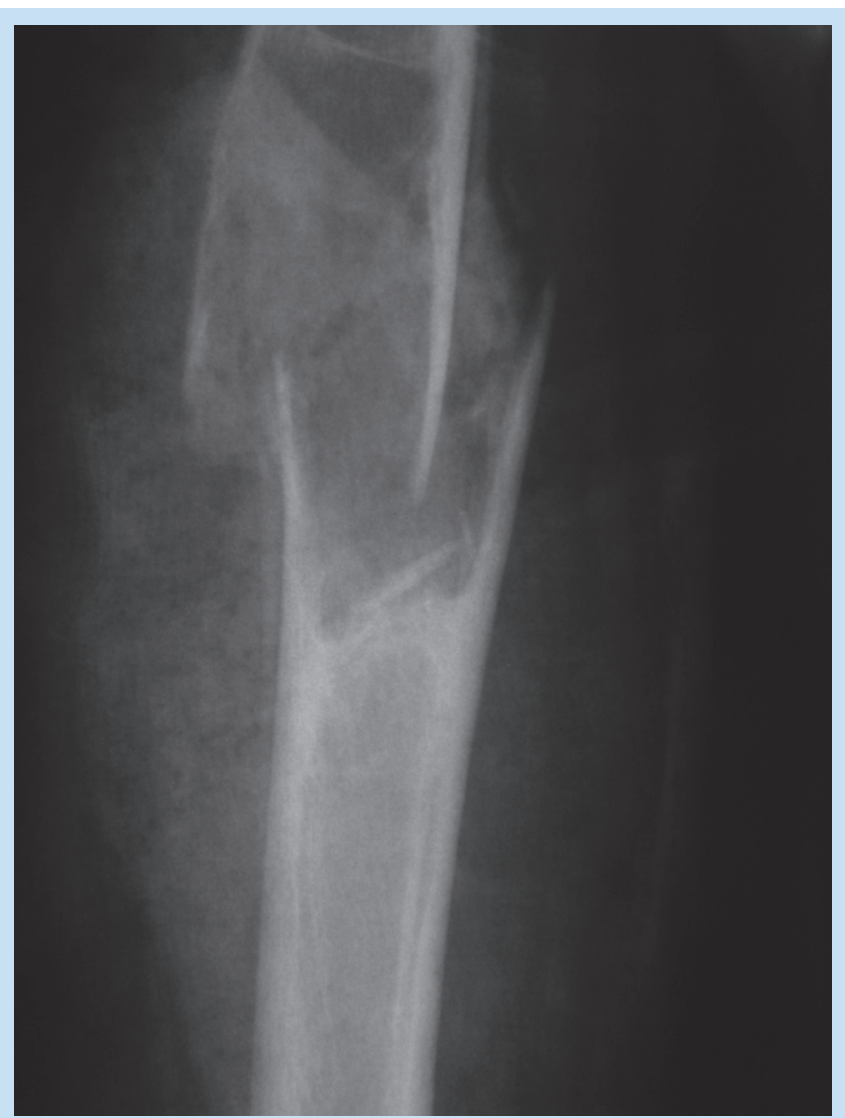

Fig. 3. As the same patient ages, the lesion is seen in the diaphysis, having moved away from the growth plate. This is typical for simple bone cysts. levels, septation and high-signal intensity (T1- and T2-weighted) of the upper fluid layer, indicative of serous fluid or extracellular methaemoglobin, strongly suggest the bone cyst in question is an aneurysmal bone cyst, rather than a unicameral bone cyst. ${ }^{8}$

1. Boseker EH, Bickel WH, Dahlin DC. A clinicopathological study of simple unicameral bone cysts. Surg Gynecol Obstet 1968; 127:550-560

2. Campanacci M, Campanna R, Picci P. Unicameral and aneurysmal bone cysts. Clin Orthop 1986; 204: 25-36.

3. Abdelwahab IF, Hermann G, Norton KI, et al. Simple bone cysts of the pelvis in adolescents. A report of four cases. J Bone Joint Surg Am 1991; 73: 1090-1094

4. Norman A, Schiffman M. Simple bone cysts: factors of age dependency. Radiology 1977; 124: 779-782.

5. Struhl A, Pritzer H, Seiman LP, et al. Solitary (unicameral) bone cyst. The fallen fragment sign revisited. Skeletal Radiol 1989; 18: 261-265.

6. Neer CS, Francis KC, Johnston AD, et al. Current concepts on the treatment of solitary unicameral bone cyst. Clin Orthop 1973; 97: 40-51

7. Baig R, Eady JL. Unicameral (simple) bone cysts. South Med J 2006; 99(9): 966-976.

8. Sullivan RJ, Meyer JS, Dormans JP, et al. Diagnosing aneurysmal and unicameral bone cysts with magnetic resonance imaging. Clin Orthop 1999; 366: 186-190.

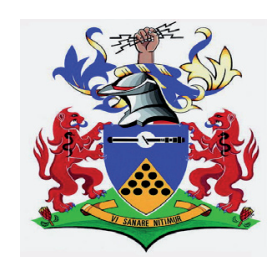

The President of the Radiological Society of South Africa (RSSA), Dr. Clive Sperryn, is pleased to announce the:

\section{RSSA CPD TRUST TRAVEL AWARD}

In order to stimulate contributions to the South African academic congress programme by junior radiologists, in South Africa, the RSSA has established a R20,000.00 prize for the best lecture given at the RSSA Biennial Congress being held in conjunction with the ISRRT World (radiographer) Congress at Durban in April 2008, by a radiology registrar or radiologist, qualified for no more than 5 years.

The award is funded by the RSSA/CPD Education Trust.

The prize money is to be used to attend an overseas congress of the winner's choice within 12 months. The winner will be required to submit a short, adequately detailed report of the congress attended to the RSSA, within 14 days of attending the congress. The report will be published on the RSSA website www.rssa.co.za

The winner will be decided by a panel of judges appointed by the RSSA Congress Chairman and review of evaluation forms completed by the audience.

Information on the Durban congress is available on www.rssa.co.za

Interested persons must submit the topic and outline of the proposed lecture, names of all contributing co-workers if applicable, affiliation and a letter of academic status. If the lecture is co-authored, a letter signed by all co-workers that the presenter has made the major contribution will be required. By submitting an entry, the applicant accepts the conditions attached to the award.

The closing date for submissions is 30 November 2007. Entries must be submitted electronically to: radsoc@iafrica.com, for the attention of Prof. Leon Janse van Rensburg. 